\title{
Determination of Mean Cell Size of Tetrahymena in Growing Cultures
}

\author{
By G. A. MORRISON AND A. L. TOMKINS \\ Edward Davies Chemical Laboratories, \\ University College of Wales, Aberystwyth, Cardiganshire
}

(Received 28 January 1972; revised 2I March 1973)

\section{SUMMARY}

The changes in volume, measured by a Coulter particle counter (the 'electronic volume'), when suspensions of Tetrahymena are diluted with aqueous electrolyte have been examined kinetically. The diluting solution can have an optimal colligative concentration in which there is initially no change of the measurement; in suboptimal concentration there is initial increase followed by a decrease to a value somewhat less than that prevailing at the moment of dilution (95\%), whereas in superoptimal concentrations there is initial decrease followed by an increase. If the initial decrease is severe the subsequent increase restores the value to only $80 \%$ of the original. The measurements of electronic volume, and of its changes, reflect the corresponding mean cell volume, and changes of it, estimated by photographic methods. The changes can be accounted for by changes of balance between the elasticity of the cell walls and the osmotic pressure across the walls.

\section{INTRODUCTION}

The present work was a necessary preliminary to an investigation of the actions of certain inhibitors of the growth of Tetrahymena pyriformis in deep culture. Microscopic observations had indicated that some of the inhibitors of the rate of increase of numbers of organisms in the cultures also caused alterations in the average size of the cells. Thus we had to be able to make concomitant measurements of the number of, and mean cell size of, the living organisms in a culture at intervals. The large number of such measurements that would be needed required the methods to be rapid. Ideally the mean cell size should be obtained directly from cells in the culture as the mean cell mass (dry wt) but this is not practicable. Withdrawal of a sample exposes the cells to a possible change of condition as subsequently may any other procedure of the method of measurement selected. The measurement of size obtained pertains to the cells under the conditions of measurement and not to cells under the cultural conditions. However, the manufacturers claim that the Coulter electronic counter can measure both the number and mean volume of particles suspended in aqueous electrolyte. The change of conditions - from suspension in the growth medium at a controlled fixed temperature to suspension in a known concentration of a particular electrolyte at possibly a different temperature - is mild, specific and reproducible. Since the mean cell volume and mean cell mass are directly related when both are measured under the same conditions, a knowledge of the relationship between the mean cell volume under the conditions of measurement by this instrument and the mean cell volume under cultural conditions would permit use of the results obtained by the instrument. This knowledge is now available and determinations of mean cell volume that are applicable to the cells in the culture are obtainable by using a Coulter counter. 


\section{METHODS}

Organisms. The strain mostly used for this work was Tetrahymena pyriformis w from the Cambridge collection. After acclimatization (details to be published) it grew optimally with a mean generation time of $2.80 \mathrm{~h}$ to $\mathrm{I} \cdot 5$ to $2 \times 10^{6}$ organisms $/ \mathrm{ml}$ at $27 \cdot 0 \pm 0 . \mathrm{I}{ }^{\circ} \mathrm{C}$ with brisk aeration ( $17 \mathrm{ml} / \mathrm{min}$ to $25 \mathrm{ml}$ culture) with sterile air containing $0.03 \%(\mathrm{v} / \mathrm{v}) \mathrm{CO}_{2}$ in medium at $\mathrm{pH} 6.00$ made up to contain: $20.0 \mathrm{~g}$ Oxoid Bacto peptone; $5.40 \mathrm{~g} \mathrm{KH}_{2} \mathrm{PO}_{4}$; $\mathrm{I} .0 \mathrm{mg}$ calcium pantothenate; $\mathrm{I} .0 \mathrm{mg}$ pyridoxine hydrochloride; $0.2 \mathrm{mg}$ biotin; $0.2 \mathrm{mg}$ thiotic acid; $10.0 \mathrm{mg} \mathrm{MgSO}_{4} .7 \mathrm{H}_{2} \mathrm{O} ; 10.0 \mathrm{mg} \mathrm{CaCl} \mathrm{CH}_{2} .6 \mathrm{H}_{2} \mathrm{O} ; 10.0 \mathrm{mg} \mathrm{CuSO} \mathrm{CH}_{4} .5 \mathrm{H}_{2} \mathrm{O} ; 5.0 \mathrm{mg}$ $\mathrm{FeCl}_{3} .6 \mathrm{H}_{2} \mathrm{O} ; 5.0 \mathrm{mg} \mathrm{MnSO}{ }_{4} \cdot 4 \mathrm{H}_{2} \mathrm{O}$; and $2.0 \mathrm{mg}$ each of guanosine; adenine, uridine and cytidine/l deionized water (conductivity less than $5 \times 10^{-7} \mathrm{mho} \mathrm{cm}^{-1}$ ) adjusted to $\mathrm{pH} 6.00$ with $\mathrm{NaOH}$ before making up to volume. The inorganic salts were all Analar, the vitamins and bases were supplied by Koch-Light Laboratories, Colnbrook, Buckinghamshire. The five other strains of Tetrahymena pyriforms used - GP, HS, T, GL and S - were also from the Cambridge collection.

The electronic particle counter and its application. A Coulter model A was fitted with a $280 \mu \mathrm{m}$ orifice tube, the gain index was set at 3 and the aperture current at 3. Calibrations were with Lycopodium spores of 27.3 and $28.5 \mu \mathrm{m}$ diam. and Silver Birch pollen of $22.96 \mu \mathrm{m}$ diam. The instrument detects decreases in the conductance of a small volume of an aqueous electrolyte drawn through the orifice when a particle is passing through; the size of the decrease is detectable, altering progressively as the threshold setting is adjusted. When the setting corresponds to detection of every particle, the total count is obtained and is correct irrespective of changes of size during treatment of a sample provided this does not cause fragmentation or aggregation. The counts at a number of different threshold settings can be used to obtain a distribution of particle volume curve and hence to calculate the mean particle volume. Alternatively the instrument can be extended with a mean particle volume computer (MCV) attachment which automatically sums the volumes of the particles passing through the orifice in $8 \mathrm{~s}$ and calculates the mean particle volume. Mean cell volumes obtained will be referred to as the electronic volume, $V_{\text {el }}$, or be expressed as $D_{\text {el }}$, the diameter of a sphere for which the instrument would give the same mean particle volume. $V_{\mathrm{el}}$ or $D_{\mathrm{el}}$ apply to the cells after dilution and any previous treatment to which they have been subjected. After more than $2 \mathrm{~h}$ from the time of dilution, the distribution curve for suspensions of Tetrahymena pyriformis $\mathrm{w}$ originally taken from cultures in their exponential phase of growth were only slightly skewed and reproducible. At the threshold setting corresponding to a value of $D_{\mathrm{el}}$ for which the instrument recorded half the total number of cells, $D_{\text {el }}$ for this setting was within $2 \%$ of that corresponding to the MCV reading. The value calculated from the whole distribution curve coincided with the latter.

\section{RESULTS}

\section{Changes of mean electronic cell volume on dilution with aqueous electrolyte}

The distribution of electronic cell volumes, and from it the value of $D_{\mathrm{el}}$ at which the count was equal to half the total, was obtained repeatedly on a sample of culture starting as soon as possible after dilution with aqueous $5.40 \mathrm{~g} \mathrm{KH}_{2} \mathrm{PO}_{4} / 1$ adjusted to $\mathrm{pH} 6.00$ with $\mathrm{NaOH}$ before making up to volume. These values of $D_{\mathrm{el}}$ decreased progressively but at a declining rate and became constant within the hour. Changing the temperature at which the measurements were made from the 20 to $21{ }^{\circ} \mathrm{C}$ of the laboratory to $27^{\circ} \mathrm{C}$, the temperature in the culture, did not alter the general result. This apparent decrease of mean electronic 


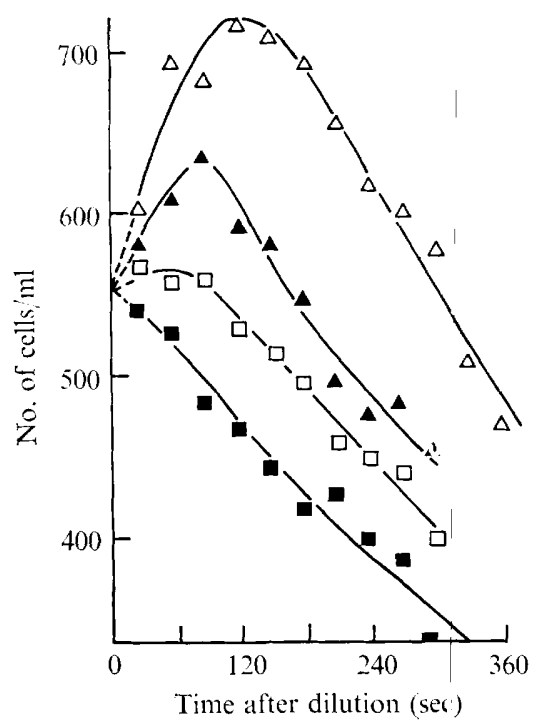

Fig. I

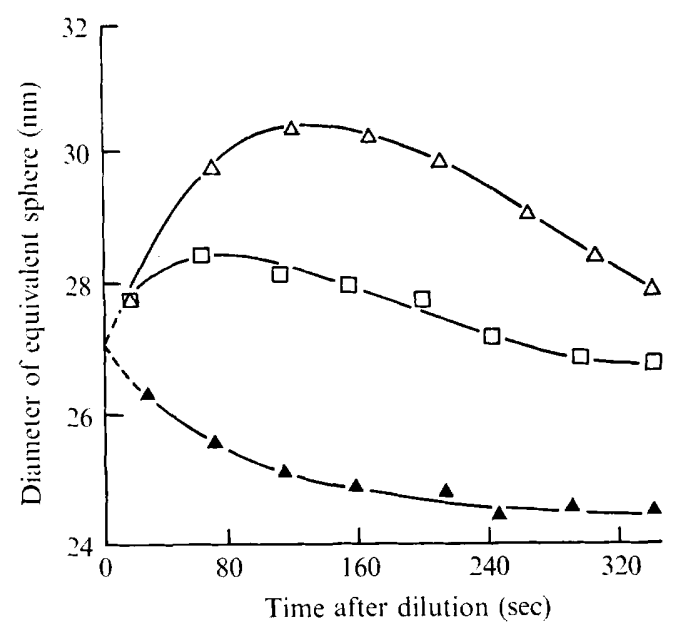

Fig. 2

Fig. I. Change of numbers of Tetrahymena pyriformis of one minimal size with time from dilution with aqueous $\mathrm{KH}_{2} \mathrm{PO}_{4}$ in $\mathrm{g} / \mathrm{l}: \Delta, 6 ; \Delta, 9 ; \square, \mathrm{I} 2 ; \mathbf{\mathrm { B }}, \mathrm{I} 5$.

Fig. 2. Change of mean volume of Tetrahymena pyriformis with time from dilution with aqueous $\mathrm{NaCl}$ at $\mathrm{I} \cdot 38(\triangle), 2 \cdot 75(\square)$ and $5 \cdot 50 \mathrm{~g} / \mathrm{l}(\Delta)$.

Table I. Variation of volume of Tetrahymena pyriformis with time after dilution with 'Bactopeptone' in $\mathrm{KH}_{2} \mathrm{PO}_{4}$ solutions

Mean diameters of equivalent spheres from mid-point of distribution in microns.

\begin{tabular}{|c|c|c|c|c|}
\hline \multirow[b]{2}{*}{$\mathrm{KH}_{2} \mathrm{PO}_{4}(\mathrm{~g} / \mathrm{l})$} & \multicolumn{4}{|c|}{ Mean diam. of cells at } \\
\hline & $\left({ }^{\circ} \mathrm{C}\right)$ & $0 \mathrm{~min}$ & $30 \mathrm{~min}$ & $\%$ change \\
\hline $5 \cdot 40$ & $2 I$ & $28 \cdot 00$ & $26 \cdot 00$ & $-7 \cdot 0$ \\
\hline 6.00 & $2 I$ & 25.90 & $24 \cdot 60$ & $-5 \cdot 2$ \\
\hline $9 \cdot 00$ & $2 I$ & $24 \cdot 40$ & $23 \cdot 20$ & $-4 \cdot 8$ \\
\hline $12 \cdot 00$ & $2 I$ & $24 \cdot 50$ & $23 \cdot 70$ & $-3 \cdot 2$ \\
\hline 9.00 & 20 & $25 \cdot 60$ & $24 \cdot 60$ & $-4 \cdot 0$ \\
\hline $9 \cdot 00$ & 27 & $26 \cdot 10$ & $25 \cdot 30$ & $-3 \cdot 0$ \\
\hline
\end{tabular}

volume was surprising since the growth medium contained $2 \%(\mathrm{w} / \mathrm{v})$ Bactopeptone and some smaller additions to the same concentrations of buffering substances; any response to the change of osmotic pressure was expected to be an expansion. The phenomenon persisted even when the diluting solution contained $2 \%(\mathrm{w} / \mathrm{v})$ Bactopeptone and higher concentrations of buffering salts (Table I). A series of experiments of this type showed that the phenomenon occurred with organisms from all stages of development of the culture, and with diluting solutions containing other electrolytes.

The threshold was left at one setting and the number of cells counted repeatedly as rapidly as possible. The results for four different concentrations of $\mathrm{KH}_{2} \mathrm{PO}_{4}$ are shown in Fig. I. At the lower concentrations the counts increased with time for between $I$ and $2.5 \mathrm{~min}$ and then decreased progressively with time; at the highest concentration they decreased progressively throughout. The precise time at which the recorded count is half the total 


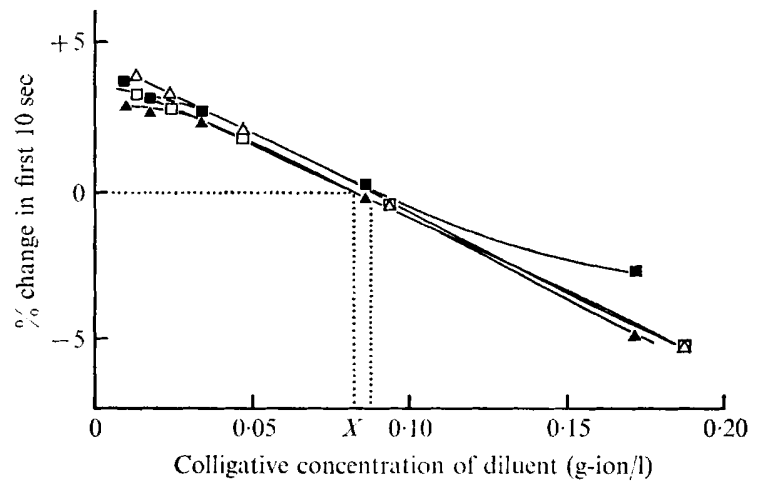

Fig. 3

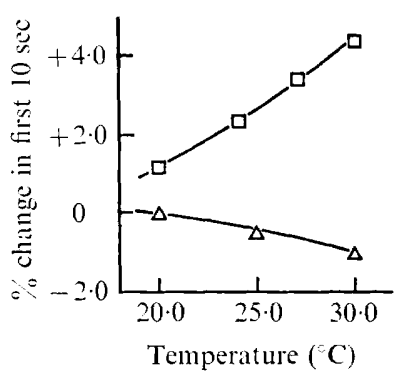

Fig. 4

Fig. 3. Dependence of initial rate of change of mean volume of Tetrahymena pyriformis on colligative concentration of electrolyte. Colligative concentration is the sum of the concentrations of the inorganic ions present. $\times$, concentration at which rate is zero, is equivalent to $4.76 \mathrm{~g} \mathrm{NaCl} / 1$.

Fig. 4. Initial rate of change of mean volume of Tetrahymena pyriformis on dilution with aqueous $\mathrm{NaCl}$ as a function of temperature. $\square, 2.75 ; \triangle, 5.50 \mathrm{~g} \mathrm{NaCl} / \mathrm{l}$.

count can be obtained by interpolation on such curves. The volume corresponding to the threshold setting is the mean $V_{\mathrm{el}} \pm 2 \%$ for the cells at that precise time. If the recording of counts for a single threshold setting is restricted to a short period in which the count passes through a value equal to half the total count, the threshold setting can be adjusted and a series of corresponding values of $V_{\mathrm{el}}$ and precise times be obtained at intervals of 40-45 $\mathrm{s}$. Fig. 2 shows the results for three different concentrations of $\mathrm{NaCl}$ as diluting solution. At the two lower concentrations of electrolyte the mean $D_{\text {el }}$ increased initially but later decreased, whereas at the highest concentration the mean $D_{\mathrm{el}}$ only decreases. The maximum extents of the expansions and their times of attainment were inverse to the actual concentration. The experiment was repeated using the MCV attachment. With the attachment a first value for the mean $D_{\text {el }}$ can be obtained at $4 \mathrm{~s}$ after dilution and subsequently others at Io s intervals, but each value depends on successive measurements of individual cells over a period of $8 \mathrm{~s}$ during which the cells are changing. The results, however, were superimposable on those obtained previously. Any errors due to the period of $8 \mathrm{~s}$ were no more significant than those arising with the half-maximum count method.

Factors affecting the initial phase of change of mean electronic volume on dilution: concentration and nature of the electrolyte, temperature and stage of growth of the culture

The initial rates of change of the mean $V_{\mathrm{el}}$, expressed as the percentage change in $\mathrm{IO} \mathrm{s}$, and the maximal percentage changes of the mean $V_{\mathrm{el}}$, were determined for cells at one stage of growth and at one temperature after dilution with a range of concentration of each of the electrolytes $\mathrm{MgSO}_{4}, \mathrm{Na}_{2} \mathrm{SO}_{4}, \mathrm{MgCl}_{2}$ and $\mathrm{NaCl}$. The results for initial rates are shown in Fig. 3. The effects on the extents of change were similar, but the distinctions for different electrolytes somewhat greater. In each case an optimal colligative concentration can be selected (equivalent to $4.76 \mathrm{~g} \mathrm{NaCl} / 1$ ) in which the initial rate of change of mean $V_{\mathrm{el}}$ is zero. Provided the concentration is not very different from the optimal one, the initial rate of change of the mean $V_{\mathrm{el}}$ and the direction of the change were directly dependent on the difference between the actual and optimal concentrations of the electrolyte. The small differences of behaviour of the four electrolytes at near optimal concentrations may be 


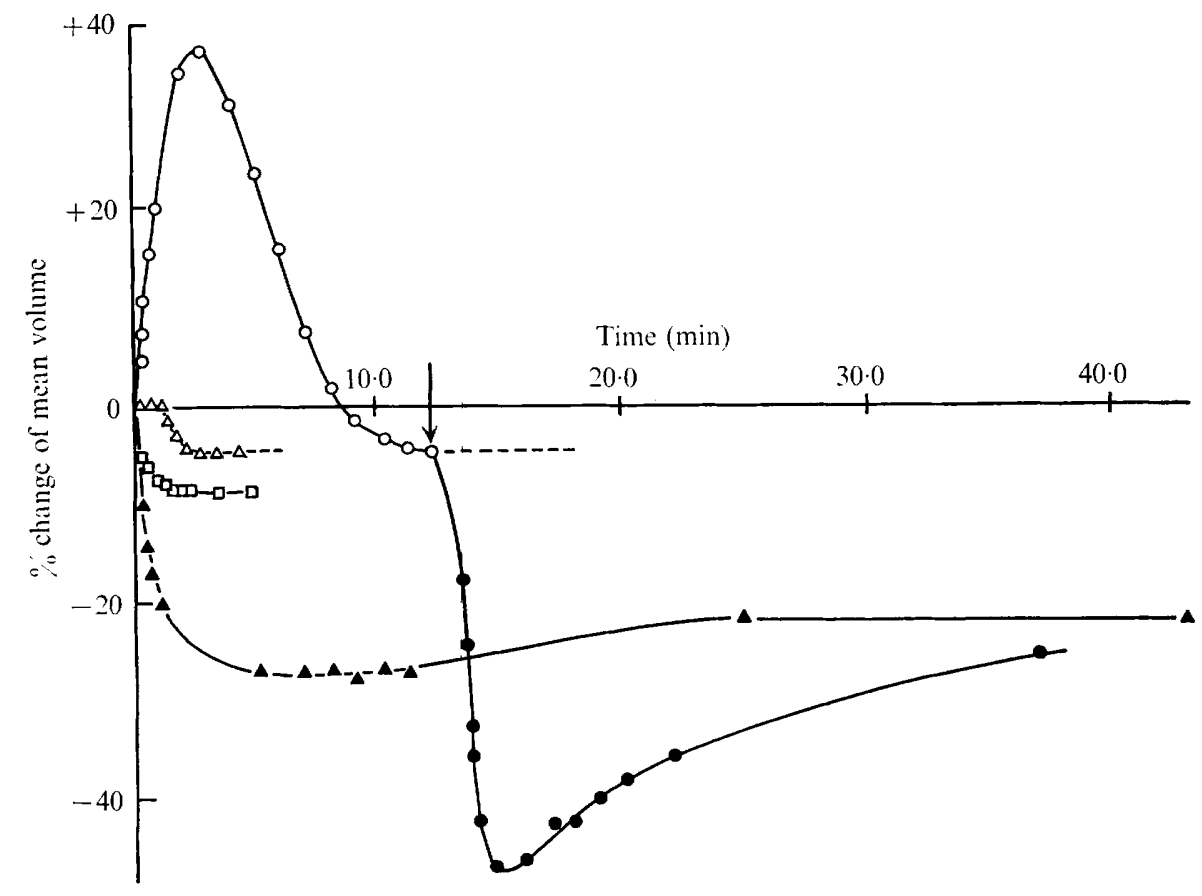

Fig. 5. Sequences of changes of mean volume of Tetrahymena pyriformis after dilution with aqueous electrolyte. $\mathrm{NaCl}$ initially $\mathrm{I} \cdot 38 \mathrm{~g} / \mathrm{l}(\mathrm{O})$; changed to $8.65 \mathrm{~g} / \mathrm{l}$ after $\mathrm{I} 4 \mathrm{~min}(\bullet), 8.65(\Delta), 4 \cdot 75(\triangle)$, $5 \cdot 50$ (口).

accounted for by three factors: (I) the use of the colligative concentration, i.e. the sum of the concentrations of the individual ions irrespective of the sign and size of their charges; and (2) the tacit assumption of no association between any pair of cation and anion present. This assumption is least likely to be justified for $\mathrm{MgSO}_{4}$. However, the association coefficient for the formation of the complex of magnesium and sulphate ions is $0.006 \mathrm{M}$ (Dunsmoore \& James, 195I) and hence even in this case the error at the maximum concentration used, $0.2 \mathrm{M}$, is less than $2 \%$. (3) The greater repulsion between doubly charged ions than between singly charged ions adsorbed on the surface. The results are as would be expected if the driving forces were osmotic. The initial rates increased with increase of temperature irrespective of the direction of change (see Fig. 4).

The back extrapolations of the graphs of mean $D_{\text {el }}$ versus time for all concentrations of one electrolyte go through the same value on the $D_{\mathrm{el}}$ ordinate (see Fig. 2). The same value was obtained speedily as the mean of four readings on the MCV attachment taken as rapidly as possible with alternating polarity across the orifice and using diluting electrolyte of optimal concentration. This is the mean value of $D_{\mathrm{el}}$ for the cells at zero time from dilution and hence the value in the culture from which they were taken.

Measurements of this mean $D_{\text {el }}$ on six portions of the same sample of a culture showed a maximum difference of $0.2 \%$ between one measurement and the average of the six when the sample was taken in the early exponential and early stationary the middle of the exponential phase; $0.4 \%$ in the log and late exponential phase; and $\mathrm{I} \cdot 2 \%$ in the late stationary phase. 


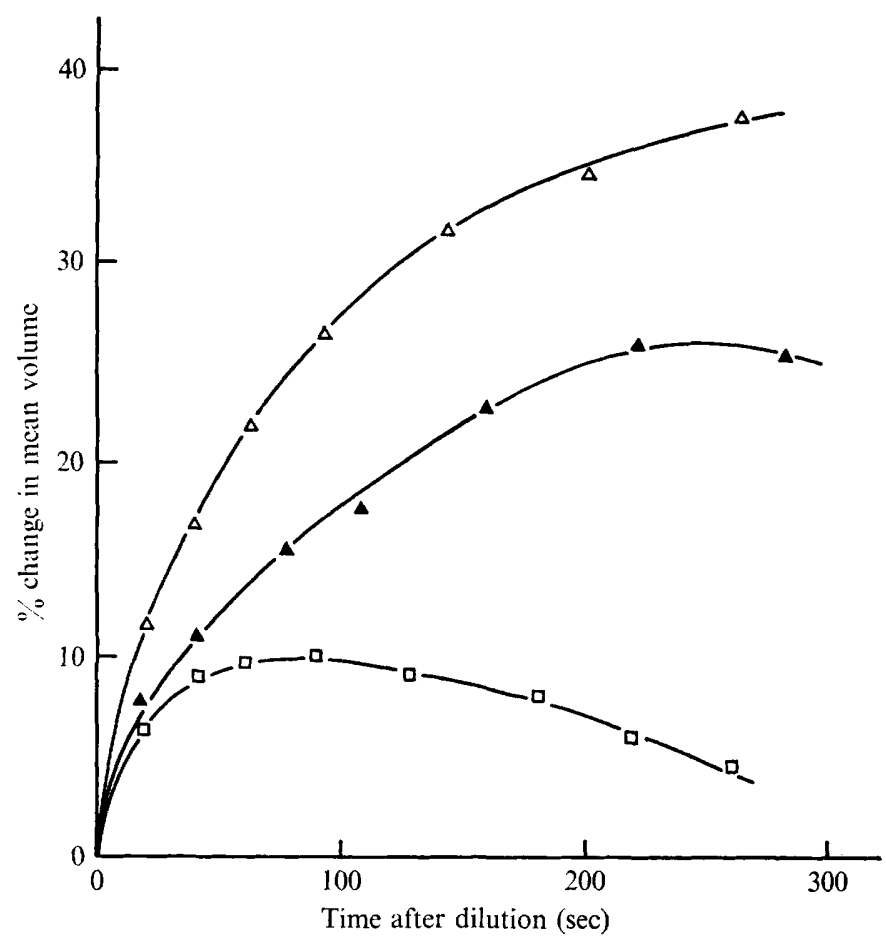

Fig. 6. Volume changes of live and dead Tetrahymena pyriformis in $2 \cdot 75 \mathrm{~g} \mathrm{NaCl} / \mathrm{l}$. Cells treated with formaldehyde: $\Delta$, momentarily; $\triangle$, for I min. Untreated cells: $\square$.

\section{Factors affecting later stages of change of mean electronic volume}

Fig. 5 compares the sequences of changes of cells in different concentrations of electrolyte. Even when the concentration was optimal so that the initial phase showed no change, the mean $V_{\mathrm{el}}$ eventually decreased to a new permanent value of $95 \%$ of the original. Additions of very small concentrations of nutrients to the diluent delayed this decrease. Similarly, after the initial increase in mean $V_{\text {el }}$ in diluents of suboptimal concentration, the mean $V_{\text {el }}$ decreased until it was $95 \%$ of the original. However, when relatively large superoptimal concentrations were used, the initial rapid decrease in mean $V_{\mathrm{el}}$ was succeeded by a slow recovery to approximately $80 \%$ of the original. This phenomenon was shown also by cells that had previously been treated in suboptimal concentrations of electrolyte and had attained a mean $V_{e l}$ of $95 \%$ of the original. Relatively small superoptimal concentrations that caused an initial decrease of mean $V_{\text {el }}$ to between 95 and $80 \%$ of the original did not recover. Thus the equilibrium mean $V_{\mathrm{el}}$ after change has stopped is $95 \%$ of the original in suboptimal concentrations, $80 \%$ of the original in highly superoptimal concentrations and between these two for moderately superoptimal concentrations.

The deviations from the linear dependence of the rates of change of mean $V_{\text {el }}$ on the colligative concentration in the diluent when this is considerably different to the optimal (Fig. 3), and the corresponding deviations of the extent of change, as well as the recoveries from the initial change, suggest that the initial changes invoke progressively opposing forces. The origin of these forces was not metabolic. Cells were grown in medium containing sufficient 'tetracyn' (the base forming tetracyline hydrochloride; Pfizer, Sandwich, Kent). Tetracyn inhibits some of the catalysts in the cell and thus alters the metabolic balance but does not 

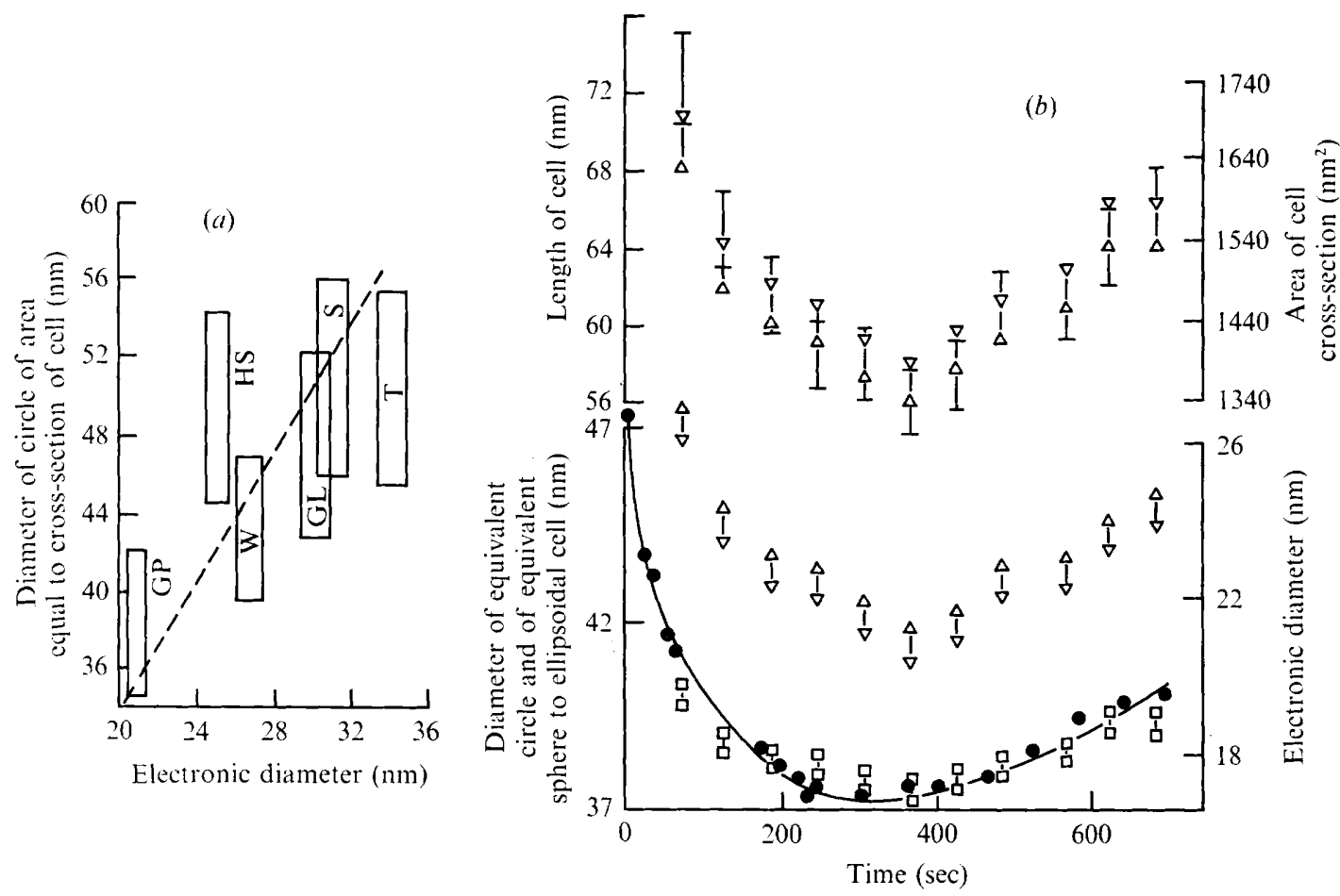

Fig. 7. (a) Comparison of diameters of circles equal in area to the mean cross-sectional area, and the diameters of spheres equal in volume to the mean electronic volume of cells of six strains of Tetrahymena pyriformis. Slope of broken line gives most probable relational coefficient. (b) Comparisons of measurement of cell length $(-\downarrow)$, cross-sectional area $(\vdash-\mid)$, and diameters of equivalent sphere [to electronic volume $(\mathbf{O})$ and to calculated ellipsoidal volume $(\square-\square)$ and of equivalent circle $(\triangleleft-\triangleright)$ ], with time from dilution with $12 \mathrm{~g} \mathrm{NaCl} /$.

affect the cell walls physically. When these cells were diluted with $2 \cdot 75 \mathrm{~g} \mathrm{NaCl} / 1$ the phenomena measured were unchanged. Neither were they changed when cells grown in ordinary medium were diluted with $2.75 \mathrm{~g} \mathrm{NaCl} / 1$ containing the same concentration of tetracyn as had the previous growth medium. Subsequently, $0.01 \mathrm{ml}$ of $50 \%(\mathrm{w} / \mathrm{v})$ aqueous formaldehyde was added to $\mathrm{I} \cdot \mathrm{O} \mathrm{ml}$ of an ordinary culture and volumes of the resultant suspension were diluted with $2.75 \mathrm{~g} \mathrm{NaCl} / 1$ at intervals of time. Even if the dilution was made as rapidly as possible the cells were killed in that they lost their mobility (live cells can move at speeds up to $\mathrm{I} \mathrm{cm} / \mathrm{sec}$ ) and could not be used as a successful inoculum of a new culture. The results are shown in Fig. 6. Cells that had just been killed showed a greater increase of mean $V_{\text {el }}$ and a slower recovery than do live cells. After I min or more of treatment with the dilute formaldehyde, the increase of mean $V_{\mathrm{el}}$ was even greater and there was no subsequent recovery. Besides destroying the catalytic power of enzymes, formaldehyde would be expected to affect the properties of the cell walls; apparently this resulted in a weakening of the abilities of the cells to resist the initial change and to recover.

\section{The relationship of electronic volume to cell volume}

The five other strains of protozoa listed earlier were acclimatised to the growth medium. Samples were taken from cultures of the five and a culture of the Tetrahymena pyriformis $\mathrm{w}$. The mean $D_{\text {el }}$ for each sample was obtained. Because of their mobility a micrometer could 
not be used to determine the dimensions of live cells under the microscope. Some of each sample was placed on a slide under a coverslip and three separate photographs taken through the microscope. Each such photograph was of a field containing between 30 and 50 organisms, and the magnification in each case was $17 \cdot 25 \times$. High-contrast enlargements then gave final pictures of the fields magnified by a factor of $255 \cdot 3$. The image of an individual protozoon was of the order of $\mathrm{I} \mathrm{cm}^{2}$. Tracings on high-quality tracing paper were made of each such picture, the outlines of each protozoon cut out carefully, and the pieces weighed on a Mettler balance accurate to $0.01 \mathrm{mg}$. By comparison with the weight of a similar number of pieces of the tracing paper of similar but known area, the mean cross-sectional area of the organisms of each strain was obtained, and expressed as the diameter of the equivalent circle. The values were assessed to have an accuracy of $\pm 10 \%$. Fig. $7(a)$ shows these results plotted against the mean $D_{\mathrm{el}}$ values. The photographically obtained dia. of the equivalent circle is $\mathrm{I} \cdot 7$ times the electronically obtained diam. of the equivalent sphere.

In a second experiment a single above-average sized Tetrahymena pyriformis $\mathrm{w}$ cell was placed in $12 \mathrm{~g} \mathrm{NaCl} / 1$ under the microscope and two photographs taken at recorded intervals of time. The magnification was $43 \cdot 125 \times$ and high-contrast enlargements increased this to $1078 \times$. The resultant tracings enclosed areas of between 15.6 and $20.2 \mathrm{~cm}^{2}$. Comparisons of the weights of the cut-out pieces with those of known areas of the same paper established the cross-sectional areas of the single organism to $\pm 3.2 \%$ and diameters of equivalent circles to $\pm \mathrm{I} \%$. The maximum lengths of the images varied between $6 \mathrm{I} \cdot 5$ and $75 \mathrm{~mm}$ corresponding to 57.0 and $69.6 \mu \mathrm{m} \pm 2 \cdot 1 \%$ and the maximum breadths of 31.5 to $34.3 \mathrm{~mm}$ corresponding to $30 \cdot 6 \mu \mathrm{m} \pm 2 \cdot 86 \%$. Since using the cross-sectional area directly is to assume the organisms are flat, from the lengths and breadth the volume of an ellipsoid of major axis equal to the determined length and of minor axis equal to the breadth, was also calculated and expressed as the diam. of an equivalent sphere. The values obtained were estimated to be accurate to $\pm 0.7 \%$. All these results for the single organism are compared with mean $D_{\text {el }}$ obtained with the Coulter counter on a sample from the same culture in Fig. $7(b)$. Clearly the changes of mean $D_{\text {el }}$ with time in the diluent reflect the changes of size of the cell.

\section{DISCUSSION}

The absolute differences between the various measurements of cell diameter compared in Fig. 7 can be accounted for: firstly the single cell chosen was above average size, and secondly the photographically based values depend on measurements in only two dimensions whereas the Coulter counter is reflecting at least the three dimensional volume. For a body of greatest length $l$, greatest width $w$, and greatest depth $d$ if $w \geqslant d$, the diam. of a sphere of volume equal to that of the body is always less than the diam. of a circle of area equal to that of the cross-section in the plane of the dimensions $l$ and $w$ unless $w=d$ and $d$ is uniform for the whole body. In the experiment the former is $0.895 \pm 0.017$ of the latter. But the former was obtained by assuming a perfect ellipsoidal shape for the cell: any flattening of the shape in the third dimension, or of the outline of the cross-section, must decrease the factor. The mean measurements on the six different strains indicate that the Coulter measurement of the mean $D_{\mathrm{el}}$ is on average 0.6 of the diam. of the circle of area equal to the mean cell cross-sectional area. The six strains were amongst those examined by Corliss (1953), who determined the average lengths of fixed organisms. The Coulter counter placed five of the strains in the same order. However, this comparison is between live cells within Ios of transfer to the diluting electrolyte and dead cells that have been treated chemically, and as pointed out by Corliss (1953), these ciliates are capable of great variations in body size, dependent upon environmental conditions. 
The volume changes occurring after dilution with suboptimal, optimal or only slightly superoptimal concentrations of electrolyte are as expected if the driving force is osmotic, the resistance to change arises from elasticity of the cell walls, and the walls allow a faster exchange of water, than of the molecules and ions in solution inside and outside the cells. The experimental evidence indicates that the changes of volume are associated with changes of the largest dimension of the cell, changes of maximum breadth being small. The net force tending to elongate the cell is the difference between the product of the osmotic pressure and the area of the cross-section perpendicular to the length at the greatest breadth, and the product of the modulus of elasticity of the walls, the circumference of the cross-section and the change in length. Since the volume of the cell is proportional to its length the rate of elongation may be expressed, whilst water but not significant amounts of solutes are entering or leaving the cell, by

$$
\begin{aligned}
\mathrm{d} l / \mathrm{d} t & =\alpha^{\prime} \Delta c A l / l_{0}-\beta^{\prime}\left(l_{0}-l\right) B \\
\quad \text { or } & =\alpha \Delta c l / l_{0}-\beta\left(l_{0}-l\right),
\end{aligned}
$$

where $\alpha^{\prime}$ is a proportionality coefficient, $\beta^{\prime}$ is the modulus of elasticity (or, - , the modulus of compression) of the walls, $l$ is the length of the cell, $l_{0}$ its length when unstressed, $A$ the area of the cross-section, $B$ its circumference, and $\Delta c$ the initial intracellular concentration minus the initial extracellular concentration of solutes.

In the original culture $l$ and $\Delta c$ have adjusted so that $\mathrm{d} l / \mathrm{d} t$ is zero, $l$ having become $l_{g}$, which is characteristic of the particular cells in the particular medium. When the cells are transferred to the electrolyte solution $\Delta c$ suddenly depends upon the concentration of solute in it. In superoptimal concentrations,

$$
\Delta c<\beta l_{g}\left(l_{g}-l_{0}\right) / \alpha l_{0}, \mathrm{~d} l / \mathrm{d} t<0
$$

and the cells shrink; in optimal concentrations,

$$
\Delta c=\beta l_{g}\left(l_{g}-l_{0}\right) / \alpha l_{0}, \mathrm{~d} l / \mathrm{d} t
$$

is zero and the cells do not change initially; in suboptimal concentrations

$$
\Delta c>\beta l_{g}\left(l_{g}-l_{0}\right) / \alpha l_{0}, \mathrm{~d} l / \mathrm{d} t>0
$$

and the cells expand. It is to be noted that in suboptimal concentrations the two terms on which $\mathrm{d} l / \mathrm{d} t$ depend are of opposite sign, whereas in superoptimal ones they are both negative: the initial rate of expansion caused by a particular positive value of $\Delta c$ should be less rapid than the shrinkage by a numerically equal but negative value of $\Delta c$. All the predicted effects are observed.

The initial solutes are of three types: molecules of ions which can diffuse through the cell walls but more slowly than the rate of exchange of water; molecules and ions which cannot pass through the cell walls by diffusion; and intermediates of the metabolism which do not have a long enough existence, before being consumed, to diffuse. In the growth medium the intermediates are being maintained from nutrients in the medium, but after dilution the nutrients are not normally available and the internal solute concentration must decrease, water leaves the cells and there is some shrinkage even when the diluent has an optimal concentration initially. The shrinkage in optimal concentration was to about $95 \%$ of the initial volume. In non-optimal concentrations the relatively slow diffusion of the solutes that can migrate through the cell walls permits the internal and external concentrations to adjust towards an equilibrium relationship. The osmotic force that caused the expansion in suboptimal concentrations or assisted the contraction in superoptimal concentrations de- 
clines and the elastic forces cause a reversal in the flow of water and consequently of the direction of change of size. Eventually an equilibrium state is attained. As internally there are solutes which cannot pass through the cell walls and the migrating solutes include ions, this equilibrium will be essentially a Donnan equilibrium modified by a pressure generated from stretching of the cell walls. Thus the eventual states in all concentrations of electrolyte would be expected to be similar. Experimentally this was so for suboptimal, optimal and relatively slightly superoptimal concentrations in which the cells finished up at about $95 \%$ of the original size. But cells compressed by more than $5 \%$ did not recover to that size, and cells that were compressed by more than $20 \%$ recovered to $80 \%$ of the original size. Possibly the large initial internal pressure associated with the rapid initial rate of shrinkage caused a loss of solution, including non-diffusible solutes, via the vacuoles of the cells, and a maximum loss in this way produced the permanent $20 \%$ decrease in size. A more detailed rationalization of the sequences of volume changes on dilution in terms of mechanical and osmotic forces is available in the library of the Edward Davies Chemical Laboratories, University College of Wales, Aberystwyth.

Several workers have used diluents containing more than one salt and additional solutes in attempts to maintain the volume of Tetrahymena: e.g. Hamburger \& Zeuthen (I957) used $2 \cdot 75 \mathrm{~g} \mathrm{NaCl} / 1+2 \cdot 75 \mathrm{~g} \mathrm{MgSO}_{4} / 1$ buffered with $5 \mathrm{mM}-\mathrm{KH}_{2} \mathrm{PO}_{4}$ and $\mathrm{NaOH}$ to $\mathrm{pH} 6.00$ and Schmidt (1962) added $0.3 \%$ albumen as well. Many mixtures of electrolytes with and without additions of albumin were tested. Qualitatively the phenomena were unchanged: in each case the variations and/or additions modified the progress plot in the way expected from the model but did not affect the sequence of events. Addition of nutrients readily used by the Tetrahymena to diluents of optimal and suboptimal concentration delayed the $5 \%$ decrease of size to the eventual equilibrium size, and always lead to an increase of cell numbers.

Thanks are due to the S.R.C. for the award to A.L.T. of a studentship, Mrs H. Griffiths for general technical assistance, and Dr M. Johnstone for manipulations of the microscope.

\section{REFERENCES}

Corliss, J. O. (1953). Comparative studies in holotrichous ciliates in the Colpedium-Gloucoma-Leuco phrys-Tetrahymena group. Parasitology 43, 49-87.

DUNSMORE, H. S. \& JAMES, J. C. (195I). The electrolyte dissociation of magnesium sulphate and lanthanum ferricyanide in mixed solvents. Journal of the Chemical Society, 2925-2930.

HambUrGer, K. \& ZeUthen, E. (1957). Sychronous division in Tetrahymena pyriformis in inorganic media. Experimental Cell Research 12, 443-453.

SchmidT, P. (I962). Temperature adaptation of the growth and division process of Tetrahymena pyriformis. Experimental Cell Research 45, 260-270. 